\title{
Investigation of in vivo cross-talk between key two-component systems of Escherichia coli
}

\author{
Daniël T. Verhamme, Jos C. Arents, Pieter W. Postma, Wim Crielaard \\ and Klaas J. Hellingwerf
}

Author for correspondence: Klaas J. Hellingwerf. Tel: +31 20 5257055. Fax: +31 205257056.

e-mail: K.Hellingwerf@chem.uva.nl

Swammerdam Institute for Life Sciences, University of Amsterdam, Nieuwe Achtergracht 166, 1018 WV Amsterdam, The Netherlands

\begin{abstract}
Intracellular signal transfer in bacteria is dominated by phosphoryl transfer between conserved transmitter and receiver domains in regulatory proteins of so-called two-component systems. Escherichia coli contains 30 such systems, which allow it to modulate gene expression, enzyme activity and the direction of flagellar rotation. The authors have investigated whether, and to what extent, these separate systems form (an) interacting network(s) in vivo, focussing on interactions between four major systems, involved in the responses to the availability of phosphorylated sugars (Uhp), phosphate (Pho), nitrogen (Ntr) and oxygen (Arc). Significant cross-talk was not detectable in wild-type cells. Decreasing expression levels of succinate dehydrogenase (reporting Arc activation), upon activation of the Pho system, appeared to be independent of signalling through PhoR. Cross-talk towards NtrC did occur, however, in a ntrB deletion strain, upon joint activation of Pho, Ntr and Uhp. UhpT expression was demonstrated when cells were grown on pyruvate, through non-cognate phosphorylation of UhpA by acetyl phosphate.
\end{abstract}

Keywords: Uhp, Pho, Ntr, Arc, non-cognate phosphoryl transfer

\section{INTRODUCTION}

Regulatory systems based on the two-component paradigm dominate the signalling machinery of bacteria, to allow them to adapt to their environment. Each system uses transient phosphorylation of sensory and regulatory proteins at a specific histidine or aspartate residue for signal transfer, and thus forms a pathway for phosphoryl transfer. Escherichia coli possesses around 30 of these pathways (Mizuno, 1997), some of which diverge, while others converge. An intriguing issue is whether cross-talk interconnects these pathways to form a (neural) network (Hellingwerf et al., 1995, 1998). Cross-talk is defined as the (modulation of) transfer of phosphoryl groups from a sensory kinase to a 'noncognate' response regulator.

This cross-talk issue was first discussed 13 years ago (Ninfa et al., 1988; Stock et al., 1989) when the abundance of two-component systems in bacteria, together with their high sequence conservation in the interaction domains of sensors and regulators, became evident. Since then several examples of cross-talk in vitro (e.g. Fisher et al., 1995; Igo et al., 1989; Ninfa et al., 1988; Yaku et al., 1997) have been reported, whereas only a few examples in E. coli have been reported of the occurrence of cross-talk in vivo (Kim et al., 1996; Matsubara \& Mizuno, 1999; McCleary et al., 1993; Ninfa et al., 1988; Silva et al., 1998; Wanner, 1992). Cross-talk is distinct from cross-regulation; in crossregulation one kinase phosphorylates more than one response regulator, as seen in chemotaxis (Hess et al., 1988), nitrate regulation (Rabin \& Stewart, 1993) and possibly between metabolic control and phosphate regulation (Wanner, 1992, 1995). Likewise, different kinases could act upon one particular response regulator.

Here we report our cross-talk studies in E. coli. An in vivo approach was used, in which one or more systems was induced and the subsequent response, if any, was monitored in another system. We examined four twocomponent systems, UhpABC, PhoBR, NtrBC and ArcAB (Fig. 1). Each of these systems plays a central role in metabolism in E. coli. The Uhp system controls the expression of the transport protein UhpT, which enables the cell to acquire phosphorylated sugars from its environment that can be used as carbon and/or energy sources (Kadner, 1995). The Pho system controls expression of the Pho regulon in response to phosphate 


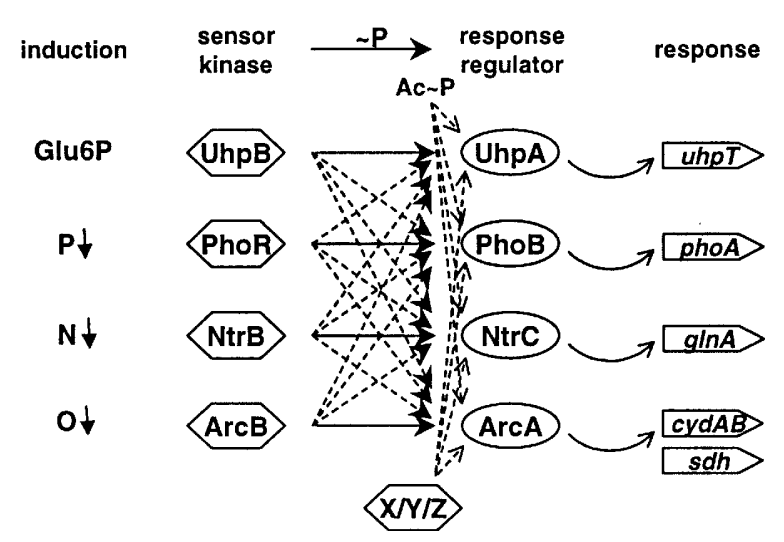

Fig. 1. Overview of all possible cross-talk interactions between the four two-component systems selected for this study. The possible roles of non-cognate sensor kinases $(X, Y$ and $Z)$ and small-molecule phosphoryl donors like acetyl phosphate $(A c \sim P)$ in response-regulator phosphorylation are also depicted. Further details are given in the text.

limitation, allowing exploitation of alternative sources of phosphate (Wanner, 1995). The Ntr system controls expression of the $g \ln A L G$ operon and other nitrogenregulated genes, in response to decreased availability of ammonia (Magasanik, 1996). The Arc system controls the expression of numerous operons involved in (an-) aerobic catabolism (Lynch \& Lin, 1996), in order to maintain respiratory homeostasis. In each of these signalling pathways the phosphorylated response regulator functions as a transcriptional modulator. In vivo activation of Uhp, Ntr and Arc can be monitored via the expression of their target genes, using lac $Z$ chromosomal fusion strains. Pho activation can be monitored via the activity of its natural target gene ( $p h o A)$, encoding alkaline phosphatase.

With regard to the above central two-component systems in E. coli, our data indicate that the specificity of the communication between domains involved in phosphoryl transfer in one pathway is much more important than the connectivity between pathways. In other words, non-cognate phosphoryl flow is of a sufficient magnitude to measurably switch on one of these systems only when cells have been mutated in the cognate kinase.

\section{METHODS}

Bacterial strains. The Escherichia coli $\mathrm{K}-12$ strains used in this study are listed in Table 1 . Strains were kindly provided by several laboratories. P1-mediated transduction was performed as described by Arber (1958). The $g \ln L$ deletion in strain PPA699 was obtained in two steps. First, a $g \ln A:: \operatorname{Tn} 5-132$ mutation was introduced into NCM3286, via selection for tetracycline resistance; this resulted in strain PPA687. The $g \ln L 2001$ deletion was subsequently introduced into PPA687 via selection for glutamine prototrophy $\left(g \ln A^{+}\right.$, i.e. recovery of the ability to grow on $\mathrm{NH}_{4}^{+}$as the sole nitrogen source). In addition to selection for the linked $(\operatorname{Tn} 10)$ tetracycline resistance, strains PPA683 and PPA703 were selected for their loss of Uhp function, i.e. no glucose-6-phosphate-induced

Table 1. E. coli strains used in this study and their relevant characteristics

\begin{tabular}{|c|c|c|}
\hline Strains & Relevant genotype & Reference or construction \\
\hline NCM3286 & $\Phi(g \ln A-\operatorname{lac} Z[\mathrm{Km}])$ & S. Kustu* \\
\hline BW12863 & $g \ln A:: \operatorname{Tn} 5-132$ & Feng et al. (1992) \\
\hline PPA687 & $\Phi(g \ln A-\operatorname{lac} Z[\mathrm{Km}]) g \ln A:: \operatorname{Tn} 5-132$ & NCM3286 × BW12863 (P1) \\
\hline RB9132 & $g \ln L 2001$ & Bueno et al. (1985) \\
\hline PPA699 & $\Phi(g \ln A-l a c Z[\mathrm{Km}]) g \ln L 2001$ & PPA687 × RB9132 (P1) \\
\hline RK1231 & $\Delta u h p(\mathrm{~A} 15-189)$ & Webber \& Kadner (1995) \\
\hline CAG18499 & zid-501::Tn10 & Singer et al. (1989) \\
\hline PPA683 & $\Delta u h p(\mathrm{~A} 15-189)$ zid-501::Tn10 & RK1231 × CAG18499 (P1) \\
\hline PPA703 & $\begin{array}{l}\Phi(g \ln A-\operatorname{lac} Z[\mathrm{Km}]) g \ln L 2001 \Delta u h p(\mathrm{~A} 15-189) \\
z i d-501:: \operatorname{Tn} 10\end{array}$ & PPA699 × PPA683 $($ P1) \\
\hline RK5115 & $\Phi(u h p T-l a c Z) \Delta u h p T$ & Shattuck-Eidens \& Kadner (1981) \\
\hline RK1307 & $\Delta u h p(\mathrm{~B} 60-\mathrm{C} 437) \Phi(u h p T-l a c Z[\mathrm{Km}])$ & Webber \& Kadner (1995) \\
\hline OG903 & $\Phi(s d h-l a c Z)$ & Matsushika \& Mizuno (1998) \\
\hline DAC903 & $\operatorname{arcB}:: \mathrm{Cm} \Phi(s d h-l a c Z)$ & Matsushika \& Mizuno (1998) \\
\hline ASA12 & $\Phi\left({ }^{\prime} c y d A-l a c Z[\mathrm{Km}]\right)$ & S. Alexeeva \\
\hline PPA718 & $\operatorname{arcB}:: \mathrm{Cm} \Phi\left({ }^{\prime} c y d A-l a c Z[\mathrm{Km}]\right)$ & ASA12 $\times$ DAC903 $(\mathrm{P} 1)$ \\
\hline PPA738 & phoR69 z::Tn10 & Yamada et al. (1989)‡ \\
\hline PPA744 & $\operatorname{arcB}:: \mathrm{Cm} \Phi(s d h-l a c Z)$ phoR69 z::Tn10 & DAC903 $\times$ PPA738 $($ P1) \\
\hline PPA747 & $\Phi(s d h-l a c Z)$ phoR69 $z:: \operatorname{Tn} 10$ & OG903 × PPA738 $(\mathrm{P} 1)$ \\
\hline
\end{tabular}

*University of California, Berkeley, CA, USA.

†Fnr box in $c y d A$ P1-promoter impaired by a 5 bp substitution (Alexeeva, 2000). Swammerdam Institute for Life Sciences.

‡Constitutive PhoR kinase phenotype. 
growth was observed with $0 \cdot 2 \%$ fructose 6 -phosphate as the carbon source (relative to growth in the presence of $0.2 \%$ glucose, on MOPS minimal medium agar plates). The $p h o R$ mutation was introduced into strains OG903 and DAC903 by co-transduction with a linked transposon $(\operatorname{Tn} 10)$ and identified by alkaline phosphatase activity, independent of phosphate limitation.

Growth conditions and activation of signalling through the two-component systems. Cells were grown in MOPS minimal medium (Neidhardt et al., 1974) containing $0.5 \%(\mathrm{v} / \mathrm{v})$ carbon source, $14 \mathrm{mM} \mathrm{NH}_{4} \mathrm{Cl}$ and $14 \mathrm{mM}$ L-glutamine as nitrogen sources, and $2 \mathrm{mM} \mathrm{K}{ }_{2} \mathrm{HPO}_{4}$ as a phosphate source. Exponentially growing (aerobic, $37^{\circ} \mathrm{C}$ ) cells were harvested by centrifugation $(3000 \mathrm{~g})$ and distributed, to a final $\mathrm{OD}_{600}$ of $\sim 0 \cdot 25$, into: (1) the same fresh medium (no activation); (2) fresh medium without $\mathrm{NH}_{4} \mathrm{Cl}$ ( $\mathrm{Ntr}$ activation); (3) fresh medium with $20 \mu \mathrm{M}$ instead of $2 \mathrm{mM} \mathrm{K}_{2} \mathrm{HPO}_{4}$ (Pho activation); and (4) fresh medium with $20 \mu \mathrm{M} \mathrm{K}_{2} \mathrm{HPO}_{4}$ and without $\mathrm{NH}_{4} \mathrm{Cl}$ (Pho and $\mathrm{Ntr}$ activation). When required, glucose 6-phosphate (Boehringer Mannheim) was added to activate the Uhp system. Samples were taken at the indicated timeintervals (Figs 2-7) up to a maximum of $150 \mathrm{~min}$ after the initiation of one of these activation protocols.

Reporter assays. $\beta$-Galactosidase and alkaline phosphatase activities were assayed as described (Michaelis et al., 1983; Miller, 1972), with minor modifications. Hydrolysis of ONPG, was assayed in cells permeabilized with SDS/ chloroform in Z buffer (Miller, 1972) and hydrolysis of $p$ nitrophenyl phosphate $(p \mathrm{NPP})$, the substrate for alkaline phosphatase, was assayed in cells permeabilized with SDS/ chloroform in $1 \mathrm{M}$ Tris $/ \mathrm{HCl}, \mathrm{pH} 8 \cdot 2$. The $\beta$-galactosidase reaction was stopped by the addition of $1 \mathrm{M} \mathrm{Na}_{2} \mathrm{CO}_{3}$; the alkaline phosphatase reaction was stopped by the addition of $1 \mathrm{M} \mathrm{KH}_{2} \mathrm{PO}_{4}$. Enzyme activities [Miller or alkaline phosphatase $(\mathrm{AP})$ units], normalized for cell density $\left(\mathrm{OD}_{600}\right)$, were calculated using the equation $\left[\left(\mathrm{OD}_{420} \times 1000\right) /(\right.$ reaction time $(\mathrm{min}) \times$ culture volume $\left.\left.(\mathrm{ml}) \times \mathrm{OD}_{600}\right)\right]$. Measurements were performed on culture samples obtained from at least two independent induction experiments, with a reproducible outcome. Typical examples are shown.

\section{RESULTS}

At face value there is ample opportunity for cross-talk between the four selected two-component systems (see Fig. 1). In each reporter strain used (Table 1), we could monitor the responses from two different signal transduction pathways: alkaline phosphatase activity, the product of $p h o A$, for Pho output, and $\beta$-galactosidase activity for any one of the other three systems. Rather than measuring the physiological reporter of Ntr, glutamine synthetase (the product of $g \ln A$ ), we also chose to use a $g \ln A-l a c Z$ reporter strain for this system. The choice of $u h p T-l a c Z$ to monitor Uhp activation was straightforward. To study Arc activation, we made use of a $s d h-l a c Z$, as well as a $c y d A-l a c Z$ reporter strain: the $s d h C D A B$ operon (encoding succinate dehydrogenase) is repressed, while $c y d A B$ (encoding cytochrome $d$ oxidase) expression is stimulated, by ArcA $\sim \mathrm{P}$ (Lynch \& Lin, 1996). In the in vivo experiments, at least one regulatory system was induced (see Methods), and the elicited responses (i.e. expression of the reporter genes) were subsequently recorded. Conditions that

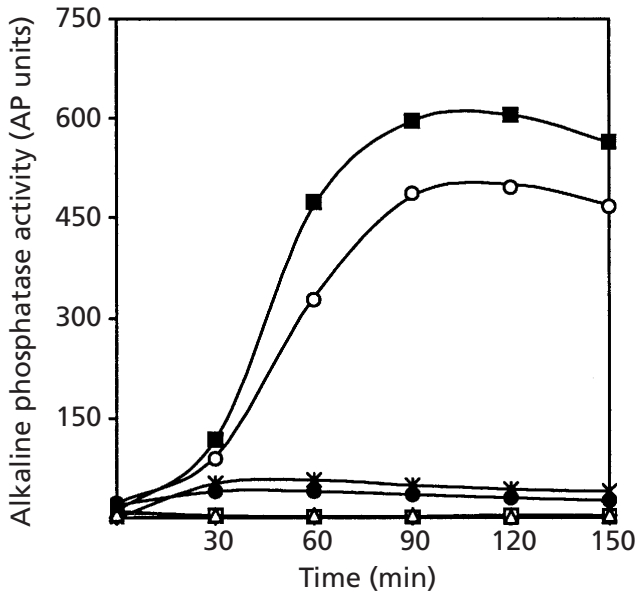

Fig. 2. Activation of the Pho system. Time course of alkaline phosphatase (AP) activity in a wild-type strain (NCM3286) grown on succinate. Growth of cells, activation of the relevant two-component system(s), sampling and calculation of alkaline phosphatase activity were carried out as described in Methods. $\diamond$, No activation; $\boldsymbol{\square}$, Pho activation; $\square$, Ntr activation; $\bigcirc$, Pho and Ntr activation; ${ }^{*}$, Pho and Uhp activation; $\triangle$, Ntr and Uhp activation; $\bullet$, Pho, Ntr and Uhp activation.

activated Arc (i.e. a limited rate of oxygen supply; Alexeeva, 2000) were not included in our analyses. Furthermore, the activated system and the system in which a co-response was measured, was either wild-type or had a deletion in the gene encoding its sensor kinase or response regulator.

\section{Cross-talk towards PhoB?}

In the wild-type background the Pho response was switched on upon phosphate limitation (Fig. 2). No Pho response was observed when only Ntr was activated, and Ntr activation suppressed Pho induction when the two systems were simultaneously induced. This latter effect was even stronger in a $\Delta n t r B$ background (data not shown). Uhp activation delayed the Pho response: addition of glucose 6-phosphate, which is a substrate for alkaline phosphatase, leads to the formation of inorganic phosphate. Simultaneous activation of Pho, Ntr and Uhp strongly suppressed the Pho response. We did not address the possibility of cross-talk to PhoB in a $\Delta p h o R$ strain. In such a background the Pho response is switched on constitutively, due to cross-regulation from CreC (Amemura et al., 1990). In addition, acetyl phosphate contributes to $\mathrm{PhoB}$ phosphorylation during growth on pyruvate (Kim et al., 1996; Wanner \& Wilmes-Riesenberg, 1992).

\section{Cross-talk towards UhpA?}

Expression of the sugar-phosphate transporter UhpT is only induced upon the presence of extracellular glucose 6-phosphate. This was evident in the uhpT-lacZ reporter strain, RK5115, upon addition of glucose 6- 

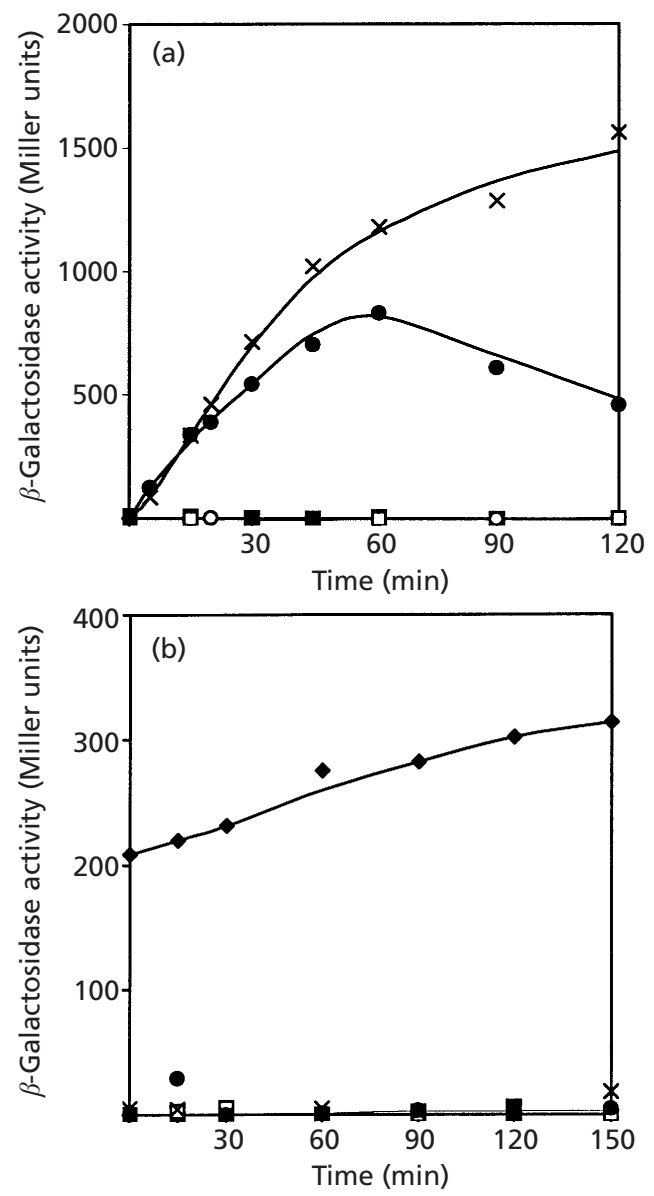

Fig. 3. Activation of the Uhp system. Time course of $\beta$ galactosidase activity of a uhpT-lacZ reporter in (a) a wild-type strain (RK5115) grown on succinate, and (b) a $\triangle u h p B C$ strain (RK1307) grown on pyruvate $(\diamond)$ or succinate (all other symbols). Twenty-five micromolar glucose 6-phosphate was used for Uhp activation and $50 \mu \mathrm{M}$ phosphate for Pho activation in (a). Growth of cells, activation of the relevant two-component system(s), sampling and calculation of $\beta$ galactosidase activity were carried out as described in Methods. $\diamond, \diamond$, No activation; $\square$, Pho activation; $\square$, Ntr activation; $\times$, Uhp activation; $O$, Pho and Ntr activation; 0 , Pho, Ntr and Uhp activation.

phosphate, during growth on succinate (Fig. 3a). Pho activation (i.e. phosphate limitation) leads to hydrolysis of the inducing signal (as described above). Clearly, in a wild-type background, no Uhp induction was observed without the addition of its activating signal. Similarly, in a Uhp-sensor deletion strain, RK1307 ( $\Delta u h p B C u h p T-$ lacZ), grown on succinate, Uhp induction could not be measured (Fig. 3b). When RK1307 was grown on pyruvate as the carbon source, however, uhpT-lacZ expression was switched on in the absence of extracellular glucose 6-phosphate (Fig. 3b). Growth on pyruvate, which is to a large extent metabolized via the Pta-AckA (phosphotransacetylase-acetate kinase) pathway (Holms, 1996), results in high intracellular levels of acetyl phosphate. This metabolite readily phosphorylates several response regulators in vitro and in vivo
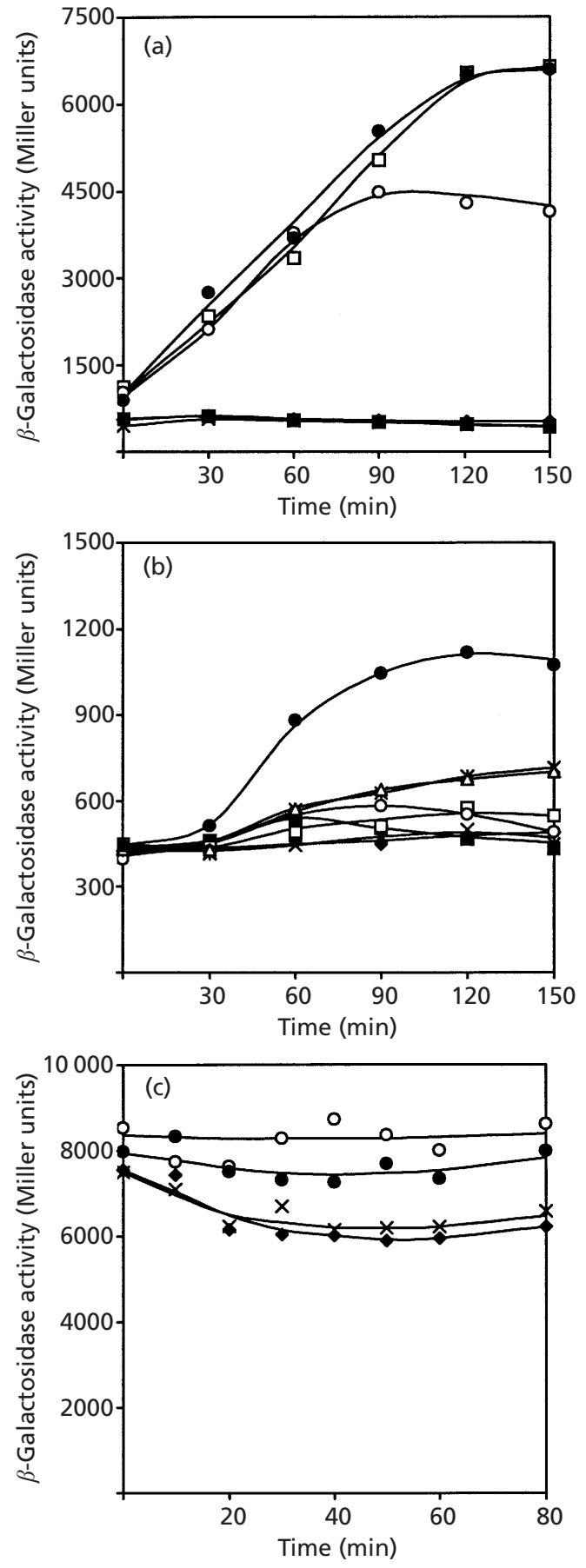

Fig. 4. Activation of the Ntr system. Time course of $\beta$ galactosidase activity of a glnA-lacZ reporter in: (a) a wild-type strain (NCM3286) grown on succinate; (b) a $\Delta n t r B$ strain (PPA699) grown on succinate; and (c) a $\Delta n t r B$ strain (PPA699) grown on pyruvate. Growth of cells, activation of the relevant two-component system(s), sampling and calculation of $\beta$ galactosidase activity were carried out as described in Methods. $\checkmark$, No activation; $\square$, Pho activation; $\square$, Ntr activation; $\times$, Uhp activation; $O$, Pho and Ntr activation; *, Pho and Uhp activation; $\triangle, \mathrm{Ntr}$ and Uhp activation; $, \mathrm{Pho}, \mathrm{Ntr}$ and Uhp activation. 

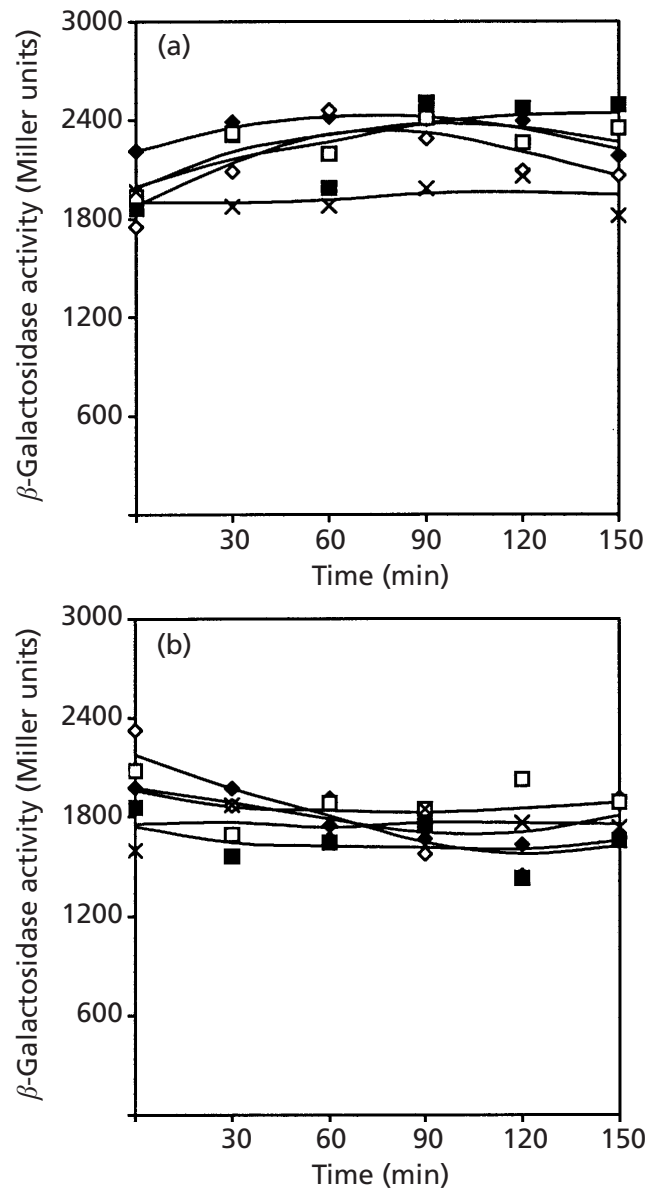

Fig. 5. Activation of the Arc system, using $c y d A-l a c Z$ as a reporter. Time course of $\beta$-galactosidase activity in (a) wild-type strain ASA12, and (b) $\triangle a r c B$ strain PPA718. Cells were grown on pyruvate $(\bullet)$ or succinate (all other symbols) as the carbon source. Growth of cells, activation of the relevant twocomponent system(s), sampling and calculation of $\beta$-galactosidase activity were carried out as described in Methods. $\bullet, \diamond$, No activation; $\square$, Pho activation; $\square$, Ntr activation; $\times$, Uhp activation.

(McCleary \& Stock, 1994; McCleary et al., 1993). Fig. 3 shows that it is also an efficient phosphoryl donor for UhpA in vivo. The level of transcription of $u h p T$ was dependent on the growth phase of the cells (data not shown), because the intracellular acetyl phosphate concentration is growth-phase dependent (McCleary \& Stock, 1994; Pruss \& Wolfe, 1994). In wild-type cells, the effect of growth on pyruvate on $u h p T-l a c Z$ expression was not observed. Under those conditions UhpB phosphatase activity hydrolyses $\mathrm{P} \sim \mathrm{UhpA}$ (this activity has also been demonstrated in vitro; Verhamme et al., 2001).

\section{Cross-talk towards NtrC?}

Nitrogen signalling, elicited by changing the nitrogen source from ammonia plus glutamine to only glutamine, induces $g \ln A$ transcription, via the NtrBC system. This Ntr response was clearly observable in wild-type strain
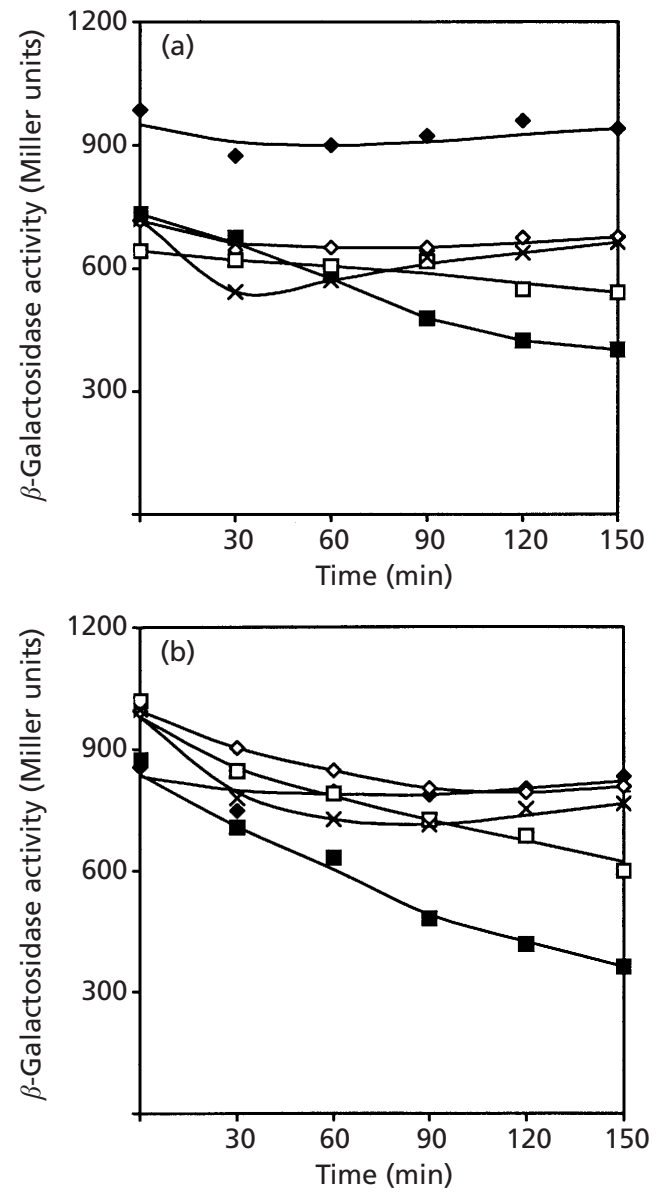

Fig. 6. Activation of the Arc system, using sdh-lacZ as a reporter. Time course of $\beta$-galactosidase activity in (a) wild-type strain OG903, and (b) $\triangle a r c B$ strain DAC903. Cells were grown on pyruvate $(\diamond)$ or succinate (all other symbols) as the carbon source. Growth of cells, activation of the relevant twocomponent system(s), sampling and calculation of $\beta$-galactosidase activity were carried out as described in Methods. $\diamond, \diamond$, No activation; $\mathbf{\square}$, Pho activation; $\square$, Ntr activation; $\times$, Uhp activation.

NCM3286 ( $g \ln A-l a c Z)$, grown on succinate (Fig. 4a). No response from the Ntr system could be monitored in this strain when either only Uhp (via addition of glucose 6-phosphate) or Pho (via phosphate limitation) was activated. Pho activation actually resulted in a suppression of $g \ln A$ transcription when Ntr and Pho were jointly activated. When three systems (i.e. Ntr, Pho and Uhp) were simultaneously activated, the inhibiting effect of Pho activation on the Ntr response was relieved, due to the presence of glucose 6-phosphate, as described above. Thus, cross-talk from Uhp and Pho to NtrC was not observed with this reporter system in a wild-type background.

We next analysed $g \ln A$ transcription in a $\Delta n t r B(g \ln L)$ background (strain PPA699) to eliminate phosphatase activity of $\mathrm{NtrB}$ towards $\mathrm{P} \sim \mathrm{NtrC}$. In this strain, nitrogen limitation can no longer be sensed, and therefore one would predict that glutamine synthetase 

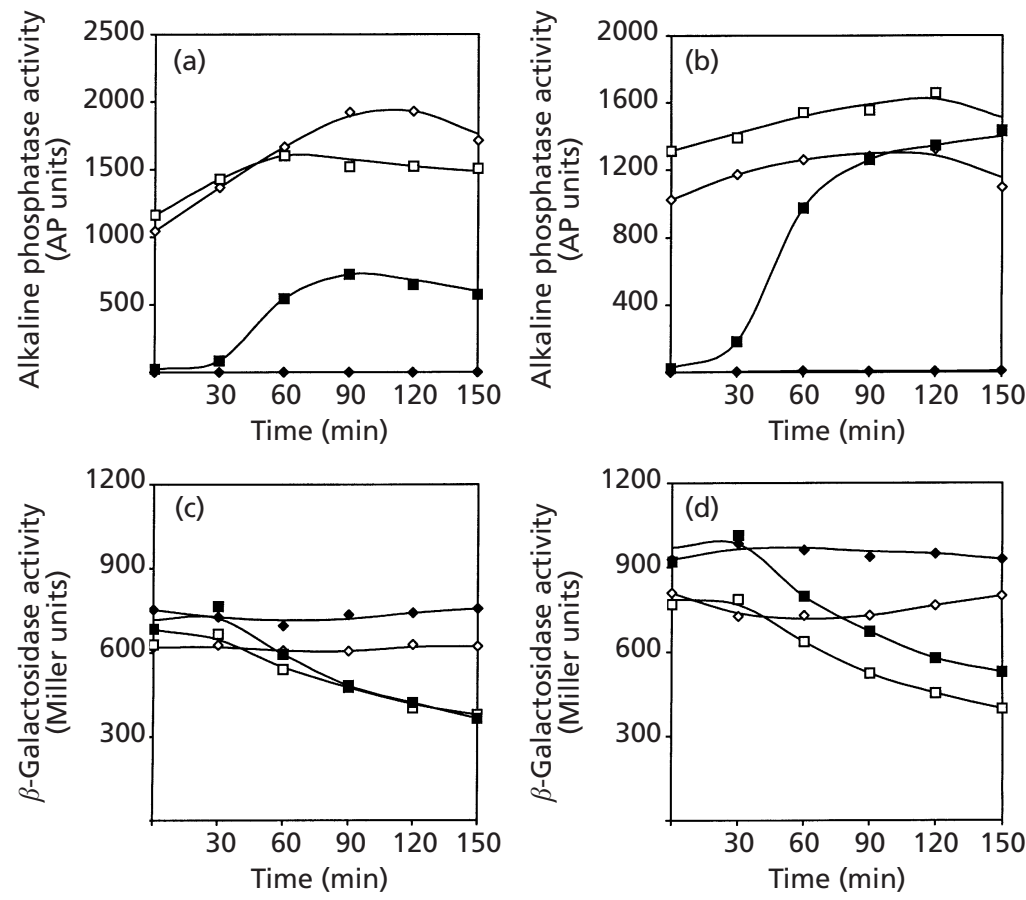

Fig. 7. Effect of phosphate limitation on $s d h$ transcription $(a, b)$. Time course of alkaline phosphatase (AP) activity in (a) a wild-type Arc background with either a wild-type PhoR kinase (OG903) or a PhoR with constitutive kinase activity (PhoR*; strain PPA747), and (b) a $\triangle \operatorname{arc} B$ background with either a wild-type PhoR (DAC903) or a constitutive kinase PhoR* (PPA744). (c, d) Time course of $s d h-l a c Z$ reporter activity in (c) a wild-type Arc background with either a wild-type PhoR kinase (OG903) or a constitutive kinase PhoR* (PPA747), and (d) a $\triangle \operatorname{arc} B$ background with either a wild-type PhoR (DAC903) or a constitutive kinase $\mathrm{PhoR}^{*}$ (PPA744). Cells were grown on succinate as the carbon source. Growth of cells, activation of the relevant two-component system(s), sampling and calculation of alkaline phosphatase activity were carried out as described in Methods. $\bullet$, No activation; 口, Pho activation; $\diamond, \mathrm{PhoR}^{*}$, no activation; $\square$, PhoR*, Pho activation. expression (as reflected in $g \ln A-l a c Z$ levels) would maximally reach the basal, non-induced level, as measured in a wild-type background. A nitrogen response, however, could still be observed in this strain (Fig. 4b) when three systems were activated simultaneously. Co-activation of two systems resulted in a slightly elevated $g \ln A$ transcription level (as compared to the level when no, or only a single, system was activated), but its statistical significance was difficult to assess.

In a 'double knock-out' strain, PPA703 ( $\Delta n t r B, \Delta u h p A)$, the absence of UhpA, in the presence of activated UhpB, did not result in a further increase of $g \ln A$ transcription (i.e. due to enhanced cross-talk from UhpB to NtrC; data not shown).

The use of pyruvate as a carbon source resulted in constitutively high glutamine synthetase expression levels in a $\Delta n t r B$ background (PPA699; Fig. 4c). Growth on pyruvate leads to an intracellular concentration of acetyl phosphate, as described above. So, NtrC can also be rapidly phosphorylated by acetyl phosphate, in the absence of NtrB (see also Feng et al., 1992). Uhp activation did not affect the Ntr response, when cells were grown on pyruvate, in a $\Delta n t r B$ background (Fig. $4 c$ ), nor in a $\Delta n t r B \Delta u h p A$ background (i.e. strain PPA703, data not shown). Pho, Ntr and Uhp coactivation in PPA699 $(\Delta n t r B)$ again resulted in an additive effect on the Ntr response (Fig. 4c), superimposed upon the stimulation by pyruvate.

\section{Cross-talk towards ArcA?}

Transcription of $c y d A B$ is both activated by $\operatorname{ArcA} \sim \mathrm{P}$ when the oxygen supply is limiting (Alexeeva, 2000; Tseng et al., 1996) and regulated by Fnr (Cotter et al., 1990). For this reason we used a modified $c y d A B$ promoter with an inactivated Fnr box (Alexeeva, 2000) in a $c y d A-l a c Z$ reporter strain. Activation of Pho, Ntr or Uhp, under aerobic conditions, did not result in an additive effect on $c y d A-l a c Z$ expression in either the wild-type (Fig. 5a), or the $\triangle \operatorname{arcB}$ (Fig. 5b) background. Also no 'pyruvate effect' (i.e. increased $c y d A B$ transcription upon growth on pyruvate) was observed in the absence of ArcB.

Activation of the Arc system represses transcription of $s d h C D A B$ (Shen \& Gunsalus, 1997). In a wild-type strain, as well as in a $\triangle \operatorname{arc} B$ strain, grown aerobically, a small additive effect on the Arc reporter (i.e. decreasing $s d h-l a c Z$ expression levels) was monitored in the first hour after induction of Uhp (i.e. until glucose 6phosphate was exhausted; Fig. 6a, b). A smaller (and delayed) effect was observed upon activation of Ntr and a rather pronounced effect (especially in the $\Delta a r c B$ strain) was observed upon activation of Pho (Fig. 6a, b). The $\Delta \operatorname{arcB}$ strain showed higher (initial) Sdh levels than the wild-type strain, implying a regulatory role for Arc under aerobic conditions, as has been observed by Park et al. (1995). Growth of the wild-type strain on pyruvate led to an increase in $s d h-l a c Z$ expression $(\sim 300$ Miller units) when compared to cells grown on succinate. In the $\Delta a r c B$ strain this expression level (Fig. 6a, b) was the same for cells grown on succinate and pyruvate. So although there was an effect of pyruvate on the Arc reporter, it was presumably not mediated through phosphorylation of ArcA by acetyl phosphate.

To further investigate whether the additive effect of Pho activation on $s d h$ expression was due to cross-talk from PhoR to ArcA we replaced the wild-type PhoR with a constitutively active PhoR* kinase (Yamada et al., 1989). This resulted in a constitutively activated Pho kinase in 
strains PPA744 and PPA747. Indeed, alkaline phosphatase was constitutively expressed at high levels in these strains (Fig. 7a, b). Therefore, if cross-talk occurs from PhoR to ArcA, sdb-lacZ expression should be reduced independently of the activation of the Pho system. However, this was not observed (Fig. 7c, d) : expression of the $s d b-l a c Z$ reporter only decreased when phosphate was limiting (i.e. upon Pho activation). Therefore, the effect of Pho activation on $s d h$ transcription must be a metabolic effect, not mediated by phosphoryl transfer from PhoR.

\section{DISCUSSION}

In this study we analysed the interactions between four major two-component regulatory systems in E. coli, to investigate to what extent cross-talk affects their responses in vivo (Fig. 1). This is relevant because considerable cross-talk between these systems would provide this bacterial signal transduction network with neural-network-like characteristics, including properties like associative memory and learning behaviour (Hellingwerf et al., 1995).

We subjected E. coli to selected signalling conditions and employed reporter constructs to monitor the response of each system separately. Using this in vivo approach we did observe cross-talk from Pho and Uhp towards NtrC, in a background in which $n t r B$ had been deleted (Fig. 4; see below). However, with this procedure, we did not detect cross-talk between these systems in a wild-type background. When the Pho and Uhp system were simultaneously activated they were indirectly mutually inhibitory. This may be true for every system co-activated with the Pho system, because of the impact that the latter system has on the energy status (ATP: ADP ratio) of the cell (Wanner, 1995). This may also be the explanation for the mutual effects of activation of Ntr and Pho.

Although we detected repression of an Arc reporter (sdh-lacZ), clearly by activation of Pho and weakly by activation of Uhp and Ntr, these effects were presumably metabolic rather than via cross-talk (Fig. 6), as was shown in more detail for the effect of phosphate limitation (Fig. 7). Sdh operates after succinyl-CoA synthetase (sucCD) in the tricarboxylic acid cycle. This latter enzyme uses phosphate as a substrate to generate ATP (Wanner, 1995). Expression of sucCD is controlled from the $s d h$ promoter (Park et al., 1997). So decreasing sucCD expression, due to substrate (i.e. phosphate) limitation, may be accompanied by decreasing $s d h$ expression.

The ArcB and PhoR transmitter, as well as the ArcA and PhoB receiver domains, belong to the same subfamily of two-component systems (Parkinson \& Kofoid, 1992). Apparently, even this additional sequence relatedness does not result in detectable cross-talk between these systems in vivo. This is consistent with the absence of cross-talk in vitro, between PhoR and ArcA (Verhamme et al., data not shown) and between ArcB and PhoB (Georgellis et al., 1999).
To avoid cognate phosphatase activity, which might obscure cross-talk towards its specific response regulator, we used kinase-deletion strains. Indeed, it was observed in the $\Delta n t r B$ background that $g \ln A-\operatorname{lac} Z$ expression was constitutive during growth on pyruvate (Fig. 4c), because of the activation of NtrC by acetyl phosphate in the absence of NtrB phosphatase activity (Feng et al., 1992). This made it very difficult to resolve whether, with growth on pyruvate, there was any additional, positive effect of activation of signalling through joint Pho, Ntr and Uhp induction. Whether or not this supplemental response is caused by cross-talk must be further investigated. Also the phenomenon that $g \ln A$ transcription is elevated upon nitrogen limitation and the co-activation of Uhp and Pho in a $\Delta n t r B$ background, during growth on succinate (Fig. 4b), should be addressed in future studies. Nitrogen regulated, NtrC-controlled $g \ln A$ transcription, independent of NtrB, has been described before (Backman et al., 1983; McFarland et al., 1981). Small amounts of acetyl phosphate in cells grown on succinate could result in limited activation of NtrC (see also Feng et al. 1992), but this does not explain the positive effect of activation of Uhp plus Pho on $g \ln A$ transcription. Furthermore, because phosphorylated $\mathrm{NtrC}$ is absolutely required for glnA transcription (Ninfa \& Magasanik, 1986), crosstalk from PhoR and UhpB may be the explanation for this observation.

UhpT was constitutively expressed in a $\triangle u h p B C$ strain when the latter was grown on pyruvate (Fig. 3b). This is a new example of response regulator activation by acetyl phosphate in vivo. This effect of growth on pyruvate is not a general phenomenon, as can be concluded from the results obtained with the Arc reporter strains in a $\triangle \operatorname{arcB}$ background (Fig. 5 and 6). Several additional response regulators are activated by acetyl phosphate in E. coli in vivo (Bouché et al., 1998; Danese et al., 1995; Dorel et al., 1999; Feng et al., 1992; Heyde et al., 2000; Matsubara \& Mizuno, 1999; McCleary \& Stock, 1994; Pruss \& Wolfe, 1994; Wanner \& WilmesRiesenberg, 1992). Significantly, only for RssB (an 'orphan' regulator involved in $\sigma^{\mathrm{s}}$ proteolysis: Bouché $e t$ al., 1998) and for OmpR, during repression of flagellar synthesis (Pruss, 1998; Pruss \& Wolfe, 1994), has this activation been shown to occur in a wild-type background for the relevant sensor kinase. The intracellular concentration of acetyl phosphate is strongly dependent on the metabolic state of the cell, as well as on growth phase, carbon source, $\mathrm{pH}$ and temperature (Heyde et al., 2000; Matsubara \& Mizuno, 1999; McCleary \& Stock, 1994; Pruss \& Wolfe, 1994). Therefore, the concentration of cytoplasmic acetyl phosphate can be regarded as a physiologically very relevant signal, feeding into the signal transduction systems of E. coli.

Considering which other two-component systems in E. coli potentially may be involved in physiologically relevant cross-talk, the CpxRA system is a candidate, because of its essential role in the extensive stressresponse network. However, it has been reported that a 'kinase-on' CpxA mutant did not measurably activate 
non-cognate response regulators (De Wulf \& Lin, 2000). In contrast, it was reported recently (Matsubara et al., 2000) that cross-talk can take place from ArcB towards OmpR. Via protein profile analysis (porin expression) and in vitro phosphorylation measurements, and with reporter assays, the ArcB-mediated and OmpR-dependent control of OmpC and $\mathrm{OmpF}$ expression, exclusively under anaerobic conditions, was demonstrated. This interaction appeared to be dependent on a functional histidine phosphoryl-transfer $(\mathrm{HPt})$ domain of the sensor kinase $\mathrm{ArcB}$ and thus reinforces the suggestion that signalling domains within multi-component phosphorelay systems (Appleby et al., 1996; Yaku et al., 1997) are potential participants in physiological crosstalk. However, in contrast, no significant cross-talk was detected between the HPt domains of BvgS and EvgS and the non-cognate response regulators $\mathrm{BvgA}$ and EvgA, either in vitro or in vivo (Beier et al., 1995; Perraud et al., 1998, 1999).

To show the subtle effects of cross-talk, existing under various conditions, the DNA microarray method may become a powerful tool in future experiments, provided that it will allow sufficiently quantitative analysis. In addition, the demonstration of the underlying change in the phosphorylation level of the relevant response regulators in vivo remains crucial for the absolute proof of the occurrence of cross-talk. However, reliable methods to monitor this phosphorylation level are not yet available. To resolve the underlying specificity in biomolecular recognition between sensor kinases and (non-cognate) response regulators in vivo, the application of two-hybrid analyses may become of crucial importance.

\section{ACKNOWLEDGEMENTS}

We thank S. Alexeeva, R. J. Kadner, S. Kustu, T. Mizuno, A. J. Ninfa and B. L. Wanner for making strains available. H. V. Westerhoff, J. Tommassen and S. M. Hoffer are gratefully acknowledged for stimulating discussions.

This work was supported by the Netherlands Organization for Scientific Research (NWO), through the division of Earth and Life Sciences (Gebied ALW).

\section{REFERENCES}

Alexeeva, S. (2000). Molecular physiology of responses to oxygen in Escherichia coli. $\mathrm{PhD}$ thesis, University of Amsterdam.

Amemura, M., Makino, K., Shinagawa, H. \& Nakata, A. (1990). Cross talk to the phosphate regulon of Escherichia coli by PhoM protein: PhoM is a histidine protein kinase and catalyzes phosphorylation of $\mathrm{PhoB}$ and PhoM-open reading frame 2. J Bacteriol 172, 6300-6307.

Appleby, J. L., Parkinson, J. S. \& Bourret, R. B. (1996). Signal transduction via the multi-step phosphorelay: not necessarily a road less traveled. Cell 86, 845-848.

Arber, W. (1958). Transduction of chromosomal genes and episomes in Escherichia coli. Virology 11, 273-288.

Backman, K. C., Chen, Y. M., Ueno-Nishio, S. \& Magasanik, B. (1983). The product of $g \ln L$ is not essential for regulation of bacterial nitrogen assimilation. J Bacteriol 154, 516-519.

Beier, D., Schwarz, B., Fuchs, T. M. \& Gross, R. (1995). In vivo characterization of the unorthodox BvgS two-component sensor protein of Bordetella pertussis. J Mol Biol 248, 596-610.

Bouché, S., Klauck, E., Fischer, D., Lucassen, M., Jung, K. \& Hengge-Aronis, R. (1998). Regulation of RssB-dependent proteolysis in Escherichia coli: a role for acetyl phosphate in a response regulator-controlled process. Mol Microbiol 27, 787795.

Bueno, R., Pahel, G. \& Magasanik, B. (1985). Role of $g \ln B$ and $g \ln D$ gene products in regulation of the $g \ln A L G$ operon of Escherichia coli. J Bacteriol 164, 816-822.

Cotter, P. A., Chepuri, V., Gennis, R. B. \& Gunsalus, R. P. (1990). Cytochrome o (cyoABCDE) and $d(c y d A B)$ oxidase gene expression in Escherichia coli is regulated by oxygen, $\mathrm{pH}$, and the fnr gene product. J Bacteriol 172, 6333-6338.

Danese, P. N., Snyder, W. B., Cosma, C. L., Davis, L. J. \& Silhavy, T. J. (1995). The Cpx two-component signal transduction pathway of Escherichia coli regulates transcription of the gene specifying the stress-inducible periplasmic protease, DegP. Genes Dev 9, 387-398.

De Wulf, P. \& Lin, E. C. (2000). Cpx two-component signal transduction in Escherichia coli: excessive CpxR-P levels underlie CpxA* phenotypes. J Bacteriol 182, 1423-1426.

Dorel, C., Vidal, O., Prigent-Combaret, C., Vallet, I. \& Lejeune, P. (1999). Involvement of the Cpx signal transduction pathway of $E$. coli in biofilm formation. FEMS Microbiol Lett 178, 169-175.

Feng, J., Atkinson, M. R., McCleary, W., Stock, J. B., Wanner, B. L. \& Ninfa, A. J. (1992). Role of phosphorylated metabolic intermediates in the regulation of glutamine synthetase synthesis in Escherichia coli. J Bacteriol 174, 6061-6070.

Fisher, S. L., Jiang, W., Wanner, B. L. \& Walsh, C. T. (1995). Crosstalk between the histidine protein kinase VanS and the response regulator PhoB. Characterization and identification of a VanS domain that inhibits activation of PhoB. J Biol Chem 270, 23143-23149.

Georgellis, D., Kwon, O. \& Lin, E. C. (1999). Amplification of signaling activity of the Arc two-component system of Escherichia coli by anaerobic metabolites. An in vitro study with different protein modules. J Biol Chem 274, 35950-35954.

Hellingwerf, K. J., Postma, P. W., Tommassen, J. \& Westerhoff, H. V. (1995). Signal transduction in bacteria: phospho-neural network(s) in Escherichia coli? FEMS Microbiol Rev 16, 309-321.

Hellingwerf, K. J., Crielaard, W. C., Joost Teixeira de Mattos, M., Hoff, W. D., Kort, R., Verhamme, D. T. \& Avignone-Rossa, C. (1998). Current topics in signal transduction in bacteria. Antonie Leeuwenhoek 74, 211-227.

Hess, J. F., Oosawa, K., Kaplan, N. \& Simon, M. I. (1988). Phosphorylation of three proteins in the signaling pathway of bacterial chemotaxis. Cell 53, 79-87.

Heyde, M., Laloi, P. \& Portalier, R. (2000). Involvement of carbon source and acetyl phosphate in the external-pH-dependent expression of porin genes in Escherichia coli. J Bacteriol 182, 198-202.

Holms, H. (1996). Flux analysis and control of the central metabolic pathways in Escherichia coli. FEMS Microbiol Rev 19, 85-116.

Igo, M. M., Ninfa, A. J. \& Silhavy, T. J. (1989). A bacterial environmental sensor that functions as a protein kinase and stimulates transcriptional activation. Genes Dev 3, 598-605.

Kadner, R. J. (1995). Expression of the Uhp sugar-phosphate transport system of Escherichia coli. In Two-Component Signal Transduction, pp. 263-274. Edited by J. A. Hoch \& T. J. Silhavy. Washington, DC: American Society for Microbiology. 
Kim, S. K., Wilmes-Riesenberg, M. R. \& Wanner, B. L. (1996). Involvement of the sensor kinase EnvZ in the in vivo activation of the response-regulator PhoB by acetyl phosphate. Mol Microbiol 22, 135-147.

Lynch, A. S. \& Lin, E. C. C. (1996). Responses to molecular oxygen. In Escherichia coli and Salmonella: Cellular and Molecular Biology, 2nd edn, pp. 1526-1538. Edited by F. C. Neidhardt and others. Washington, DC: American Society for Microbiology.

McCleary, W. R. \& Stock, J. B. (1994). Acetyl phosphate and the activation of two-component response regulators. J Biol Chem 269, 31567-31572.

McCleary, W. R., Stock, J. B. \& Ninfa, A. J. (1993). Is acetyl phosphate a global signal in Escherichia coli? J Bacteriol 175, 2793-2798.

McFarland, N., McCarter, L., Artz, S. \& Kustu, S. (1981). Nitrogen regulatory locus $g \ln R$ of enteric bacteria is composed of cistrons $n t r B$ and $n t r C$ : identification of their protein products. Proc Natl Acad Sci U S A 78, 2135-2139.

Magasanik, B. (1996). Regulation of nitrogen utilization. In Escherichia coli and Salmonella: Cellular and Molecular Biology, 2nd edn, pp. 1344-1356. Edited by F. C. Neidhardt and others. Washington, DC: American Society for Microbiology.

Matsubara, M. \& Mizuno, T. (1999). EnvZ-independent phosphotransfer signaling pathway of the OmpR-mediated osmoregulatory expression of $\mathrm{OmpC}$ and $\mathrm{OmpF}$ in Escherichia coli. Biosci Biotechnol Biochem 63, 408-414.

Matsubara, M., Kitaoka, S. I., Takeda, S. I. \& Mizuno, T. (2000). Tuning of the porin expression under anaerobic growth conditions by His-to-Asp cross-phosphorelay through both the EnvZosmosensor and ArcB-anaerosensor in Escherichia coli. Genes Cells 5, 555-569.

Matsushika, A. \& Mizuno, T. (1998). A dual-signaling mechanism mediated by the ArcB hybrid sensor kinase containing the histidine-containing phosphotransfer domain in Escherichia coli. J Bacteriol 180, 3973-3977.

Michaelis, S., Inouye, H., Oliver, D. \& Beckwith, J. (1983). Mutations that alter the signal sequence of alkaline phosphatase in Escherichia coli. J Bacteriol 154, 366-374.

Miller, J. H. (1972). Experiments in Molecular Genetics. Cold Spring Harbor, NY : Cold Spring Harbor Laboratory.

Mizuno, T. (1997). Compilation of all genes encoding twocomponent phosphotransfer signal transducers in the genome of Escherichia coli. DNA Res 4, 161-168.

Neidhardt, F. C., Bloch, P. L. \& Smith, D. F. (1974). Culture medium for enterobacteria. J Bacteriol 119, 736-747.

Ninfa, A. J. \& Magasanik, B. (1986). Covalent modification of the $g \ln G$ product, NRI, by the $g \ln L$ product, NRII, regulates the transcription of the $g \ln A L G$ operon in Escherichia coli. Proc Natl Acad Sci U S A 83, 5909-5913.

Ninfa, A. J., Ninfa, E. G., Lupas, A. N., Stock, A., Magasanik, B. \& Stock, J. (1988). Crosstalk between bacterial chemotaxis signal transduction proteins and regulators of transcription of the Ntr regulon: evidence that nitrogen assimilation and chemotaxis are controlled by a common phosphotransfer mechanism. Proc Natl Acad Sci U S A 85, 5492-5496.

Park, S. J., Tseng, C. P. \& Gunsalus, R. P. (1995). Regulation of succinate dehydrogenase $(s d h C D A B)$ operon expression in Escherichia coli in response to carbon supply and anaerobiosis: role of ArcA and Fnr. Mol Microbiol 15, 473-482.

Park, S. J., Chao, G. \& Gunsalus, R. P. (1997). Aerobic regulation of the sucABCD genes of Escherichia coli, which encode alphaketoglutarate dehydrogenase and succinyl coenzyme A syn- thetase: roles of ArcA, Fnr, and the upstream $s d h C D A B$ promoter. J Bacteriol 179, 4138-4142.

Parkinson, J. S. \& Kofoid, E. C. (1992). Communication modules in bacterial signaling proteins. Annu Rev Genet 26, 71-112.

Perraud, A. L., Kimmel, B., Weiss, V. \& Gross, R. (1998). Specificity of the BvgAS and EvgAS phosphorelay is mediated by the Cterminal HPt domains of the sensor proteins. Mol Microbiol 27, 875-887.

Perraud, A. L., Weiss, V. \& Gross, R. (1999). Signalling pathways in two-component phosphorelay systems. Trends Microbiol 7, 115-120.

Pruss, B. M. (1998). Acetyl phosphate and the phosphorylation of OmpR are involved in the regulation of the cell division rate in Escherichia coli. Arch Microbiol 170, 141-146.

Pruss, B. M. \& Wolfe, A. J. (1994). Regulation of acetyl phosphate synthesis and degradation, and the control of flagellar expression in Escherichia coli. Mol Microbiol 12, 973-984.

Rabin, R. S. \& Stewart, V. (1993). Dual response regulators (NarL and $\mathrm{NarP}$ ) interact with dual sensors ( $\mathrm{NarX}$ and $\mathrm{NarQ}$ ) to control nitrate- and nitrite-regulated gene expression in Escherichia coli K-12. J Bacteriol 175, 3259-3268.

Shattuck-Eidens, D. M. \& Kadner, R. J. (1981). Exogenous induction of the Escherichia coli hexose phosphate transport system defined by $u h p-l a c$ operon fusions. J Bacteriol 148, 203-209.

Shen, J. \& Gunsalus, R. P. (1997). Role of multiple ArcA recognition sites in anaerobic regulation of succinate dehydrogenase $(s d h C D A B)$ gene expression in Escherichia coli. Mol Microbiol 26, 223-236.

Silva, J. C., Haldimann, A., Prahalad, M. K., Walsh, C. T. \& Wanner, B. L. (1998). In vivo characterization of the type $\mathrm{A}$ and $\mathrm{B}$ vancomycin-resistant enterococci (VRE) VanRS two-component systems in Escherichia coli: a nonpathogenic model for studying the VRE signal transduction pathways. Proc Natl Acad Sci U S A 95, 11951-11956.

Singer, M., Baker, T. A., Schnitzler, G. \& 7 other authors (1989). A collection of strains containing genetically linked alternating antibiotic resistance elements for genetic mapping of Escherichia coli. Microbiol Rev 53, 1-24.

Stock, J. B., Ninfa, A. J. \& Stock, A. M. (1989). Protein phosphorylation and regulation of adaptive responses in bacteria. Microbiol Rev 53, 450-490.

Tseng, C. P., Albrecht, J. \& Gunsalus, R. P. (1996). Effect of microaerophilic cell growth conditions on expression of the aerobic (cyoABCDE and $c y d A B$ ) and anaerobic (narGHJI, frd $A B C D$, and $d m s A B C$ ) respiratory pathway genes in Escherichia coli. J Bacteriol 178, 1094-1098.

Verhamme, D. T., Arents, J. C., Postma, P. W., Crielaard, W. \& Hellingwerf, K. J. (2001). Glucose-6-phosphate-dependent phosphoryl flow through the Uhp two-component regulatory system. Microbiology 147, 3345-3352.

Wanner, B. L. (1992). Is cross regulation by phosphorylation of two-component response regulator proteins important in bacteria? J Bacteriol 174, 2053-2058.

Wanner, B. L. (1995). Signal transduction and cross regulation in the Escherichia coli phosphate regulon by PhoR, CreC and acetyl phosphate. In Two-component Signal Transduction, pp. 203-221. Edited by J. A. Hoch \& T. J. Silhavy. Washington, DC: American Society for Microbiology.

Wanner, B. L. \& Wilmes-Riesenberg, M. R. (1992). Involvement of phosphotransacetylase, acetate kinase, and acetyl phosphate synthesis in control of the phosphate regulon in Escherichia coli. J Bacteriol 174, 2124-2130. 
Webber, C. A. \& Kadner, R. J. (1995). Action of receiver and activator modules of UhpA in transcriptional control of the Escherichia coli sugar phosphate transport system. Mol Microbiol 15, 883-893.

Yaku, H., Kato, M., Hakoshima, T., Tsuzuki, M. \& Mizuno, T. (1997). Interaction between the CheY response regulator and the histidine-containing phosphotransfer $(\mathrm{HPt})$ domain of the ArcB sensory kinase in Escherichia coli. FEBS Lett 408, 337-340.
Yamada, M., Makino, K., Amemura, M., Shinagawa, H. \& Nakata, A. (1989). Regulation of the phosphate regulon of Escherichia coli: analysis of mutant $p h o B$ and $p h o R$ genes causing different phenotypes. J Bacteriol 171, 5601-5606.

Received 23 July 2001; revised 13 September 2001; accepted 27 September 2001. 